\title{
Fatal SARS-CoV-2 infection in a renal transplant recipient
}

\author{
Ahmet Burak Dirim ${ }^{1}$ (D) Erol Demir ${ }^{1} \cdot$ Ali Riza Ucar $^{1} \cdot$ Nurana Garayeva $^{1} \cdot$ Seda Safak ${ }^{1}$. Ozgur Akin Oto $\cdot$ Halil Yazici $^{1}$. \\ Alpay Medet Alibeyoglu ${ }^{2} \cdot$ Gunseli Orhun ${ }^{3} \cdot$ Arif Atahan Cagatay $^{4} \cdot$ Aydin Turkmen $^{1}$
}

Received: 13 May 2020 / Accepted: 10 June 2020 / Published online: 20 June 2020

(c) Japanese Society of Nephrology 2020

\begin{abstract}
The severe acute respiratory syndrome coronavirus 2 (SARS-CoV 2) caused a pandemic that first discovered in Wuhan, China. While $10 \%$ of the patients have asymptomatic infection, $15-20 \%$ have lung involvement, $5-10 \%$ have multiple organ failure, and macrophage activation syndrome. Chronic respiratory diseases, diabetes mellitus, hypertension, and cancer are risk factors for mortality. Prognosis or optimal treatment strategy for renal transplant recipients in SARS-CoV-2 infection is still unknown. Besides fatal cases, there were also milder case reports. In addition, COVID-19 treatment and the maintenance immunosuppression strategy is still under debate. Antiviral therapies and drug interactions are special topics for these patients. To the best of our knowledge, favipiravir and anti-cytokine treatments have not been previously reported in a kidney transplant recipient with SARS-CoV-2 infection before. We report a case of SARS-CoV-2 infection in a kidney transplant recipient with fatal outcomes.
\end{abstract}

Keywords COVID-19 $\cdot$ Renal transplantation $\cdot$ Treatment

\section{Introduction}

The severe acute respiratory syndrome coronavirus-2 (SARS-CoV-2) caused a pandemic that first discovered in Wuhan, China. This virus enters the cell via the angiotensinconverting enzyme II in the lung, and the upper respiratory tract causes Coronavirus disease 2019 (COVID-19) infection. While $10 \%$ of the patients have asymptomatic infection, 15-20\% have lung involvement, 5-10\% have multiple organ failure, and macrophage activation syndrome [1-3].

Chronic respiratory diseases, diabetes mellitus, hypertension, and cancer are risk factors for mortality. The risk

Ahmet Burak Dirim

ahmetburakdirim@gmail.com

1 Division of Nephrology, Department of Internal Medicine, Istanbul Faculty of Medicine, Istanbul University, Istanbul, Turkey

2 Department of Internal Medicine, Istanbul Faculty of Medicine, Istanbul University, Istanbul, Turkey

3 Department of Anesthesiology and Intensive Care, Istanbul Faculty of Medicine, Istanbul University, Istanbul, Turkey

4 Department of Infectious Diseases and Clinical Microbiology, Istanbul Faculty of Medicine, Istanbul University, Istanbul, Turkey of infection increases in kidney transplant recipients due to immunosuppressive therapy, comorbidity, and residual chronic kidney disease [2]. However, prognosis or optimal treatment strategy for renal transplant recipients in SARSCoV-2 infection is still unknown. Besides fatal cases, there were also milder case reports. Additionally, COVID-19 treatment and the maintenance immunosuppression strategy is still under debate. Antiviral therapies and drug interactions are special topics for these patients. To the best of our knowledge, favipiravir and anti-cytokine treatments have not been previously reported in a kidney transplant recipient with SARS-CoV-2 infection before. We report a case of SARS-CoV-2 infection in kidney transplant recipients with fatal outcomes.

\section{Case report}

A 55-year old female kidney transplant recipient admitted to the emergency clinic with symptoms of cough, dyspnea, and fever for one week. She was diagnosed with chronic glomerulonephritis 20 years ago. The disease progressed to end-stage kidney disease 16 years ago, so she had a cadaveric donor transplant operation after a decade of hemodialysis. Pre-transplant viral serology was negative for both donor 
and recipient regarding hepatitis $\mathrm{B}$, hepatitis $\mathrm{C}$, and human immunodeficiency virus, while seropositive for Epstein Barr virus, Cytomegalovirus, and Varicella Zoster virus, each. The immunosuppressive regimen consists of a combination of tacrolimus, mycophenolate mofetil, and prednisolone. The post-transplant five years was uneventful. The patient had been receiving losartan $50 \mathrm{mg} /$ day due to hypertension. Most recent laboratory tests were measured a month ago before admission and demonstrated serum creatinine: $1 \mathrm{mg} /$ $\mathrm{dL}$, and high-sensitivity C-reactive protein: $6.2 \mathrm{mg} / \mathrm{L}$.

On physical examination, the patient was tachypneic, bilateral fine crackles were detected on chest auscultation. The temperature was $38{ }^{\circ} \mathrm{C}$, blood pressure was $120 / 80 \mathrm{mmHg}$, and respiratory rate was $28 / \mathrm{min}$. Oxygen saturation was $98 \%$ in the room air. Laboratory data showed that white blood cell: $5850 / \mathrm{mm}^{3}$, neutrophil: $4710 / \mathrm{mm}^{3}$, lymphocyte: $620 / \mathrm{mm}^{3}$, haemoglobin: $12.5 \mathrm{~g} / \mathrm{dL}$, platelet: $205,000 / \mathrm{mm}^{3}$, serum creatinine: $1.4 \mathrm{mg} / \mathrm{dL}$, lactate dehydrogenase: $342 \mathrm{U} / \mathrm{L}$, ferritin: $3125 \mathrm{ng} / \mathrm{mL}$, triglyceride: $190 \mathrm{mg} /$ $\mathrm{dL}$, aspartate transaminase: $33 \mathrm{IU} / \mathrm{mL}$, alanine transaminase: $19 \mathrm{IU} / \mathrm{mL}$, procalcitonin: $0.06 \mathrm{ng} / \mathrm{mL}$, albumin: $4.32 \mathrm{~g} / \mathrm{dL}$, total protein: $7.08 \mathrm{~g} / \mathrm{dL}$, high-sensitivity $\mathrm{C}$-reactive protein: $44.9 \mathrm{mg} / \mathrm{L}$, cardiac troponin: $0.02 \mu \mathrm{g} / \mathrm{L}, \mathrm{N}$-terminal proBNP: $30 \mathrm{pg} / \mathrm{mL}$, and D-dimer: $950 \mathrm{ng} / \mathrm{mL}$.

A rapid nucleic acid amplification test with the nasopharyngeal swab was performed for SARS-CoV-2 and common lower respiratory tract infections such as influenza, parainfluenza, rhinovirus, adenovirus, and was found negative. Blood and sputum cultures have been identified as negative for bacterial pathogens such as Streptococcus pneumonia. In addition, the polymerase chain reaction (PCR) for Cytomegalovirus DNA of serum resulted in negative. The patient reported a history of contact with his brother, who was hospitalized for 7 days and died from COVID-19. During this time, the patient visited his brother in the hospital. We assumed this situation as an intense contact. Chest computed tomography showed bilateral ground-glass opacities (Fig. 1). The patient was diagnosed with COVID-19 due to contact history, clinical presentation, laboratory, radiological findings, and high rate of false negative results in the viral PCR test. The cytokine levels were not measured because the test was not available in our hospital. Mycophenolate mofetil was stopped and tacrolimus dose was halved. The patient treated with hydroxychloroquine (400 mg BID for the first day, $200 \mathrm{mg}$ BID for the second to fifth days; oral) and azithromycin (500 mg QD for the first day, $250 \mathrm{mg}$ QD for the second to fifth days; oral).

Hypoxemia was developed seven days after the hospitalization despite nasal high-flow oxygen therapy. The patient was intubated in the intensive care unit (ICU). Also, favipiravir (1600 mg BID for the first day, afterward $600 \mathrm{mg}$ BID; oral for 5 days), tocilizumab ( $400 \mathrm{mg}$ QD; intravenous for 2 days), and intravenous immunoglobulin (IVIG) ( $2 \mathrm{~g} / \mathrm{kg}$;

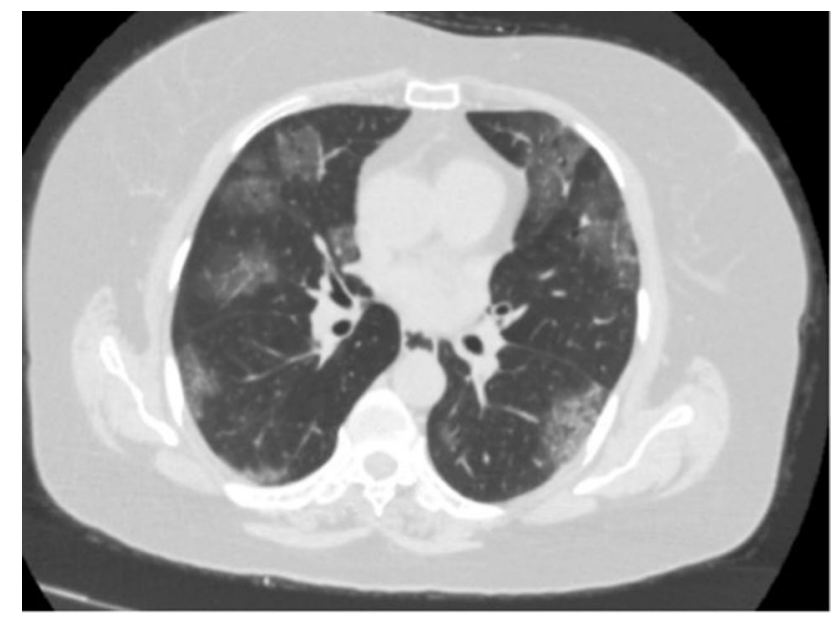

Fig. 1 Initial axial chest computed tomography images show confluent ground-glass opacities involving both lungs

divided doses in 5 days) treatments were initiated. Despite negative microbiological cultures, empirical broad-spectrum antibiotics (meropenem and teicoplanin) were started. Hypotension developed 9 days after the first symptoms, and noradrenaline was started. Serum creatinine increased to $1.8 \mathrm{mg} / \mathrm{dL}$, oliguria, and metabolic acidosis developed, and continuous venovenous hemodiafiltration (CVVHDF) was started. The course of serum ferritin, lactate dehydrogenase, C-reactive protein, and response to various therapeutic interventions are shown in Fig. 2. In addition, hemadsorption was initiated with CytoSorb ${ }^{\circledR}$ (CytoSorbents Europe $\mathrm{GmbH}$, Berlin, Germany) for the treatment of cytokine storm. The patient died due to multiorgan failure as a consequence of cytokine storm in the ICU on the 10th day of the emergency service admission.

\section{Discussion}

The SARS-CoV-2 infection diagnosis relies mainly on contact history, clinical features, laboratory, and radiological findings. The most frequent symptoms are fever and cough. Lymphopenia and ground glass pneumonic opacities in chest tomography are the most common laboratory and radiological findings, respectively. Positive real-time PCR test from nasal and throat swab samples can confirm the diagnosis [3]. However, up to $30 \%$ of false-negative rates reported for the PCR test [4]. Also, in another study, false-negative rates were observed more frequently at late admission and with throat swab tests when compared to nasal swabs [5]. We made the diagnosis of SARS-CoV-2 infection along with a history of contact, clinical characteristics, laboratory, and radiological findings in our patient. We thought of false-negative PCR results could be associated with late 
Fig. 2 The course of serum ferritin, lactate dehydrogenase, C-reactive protein, and response to various therapeutic interventions

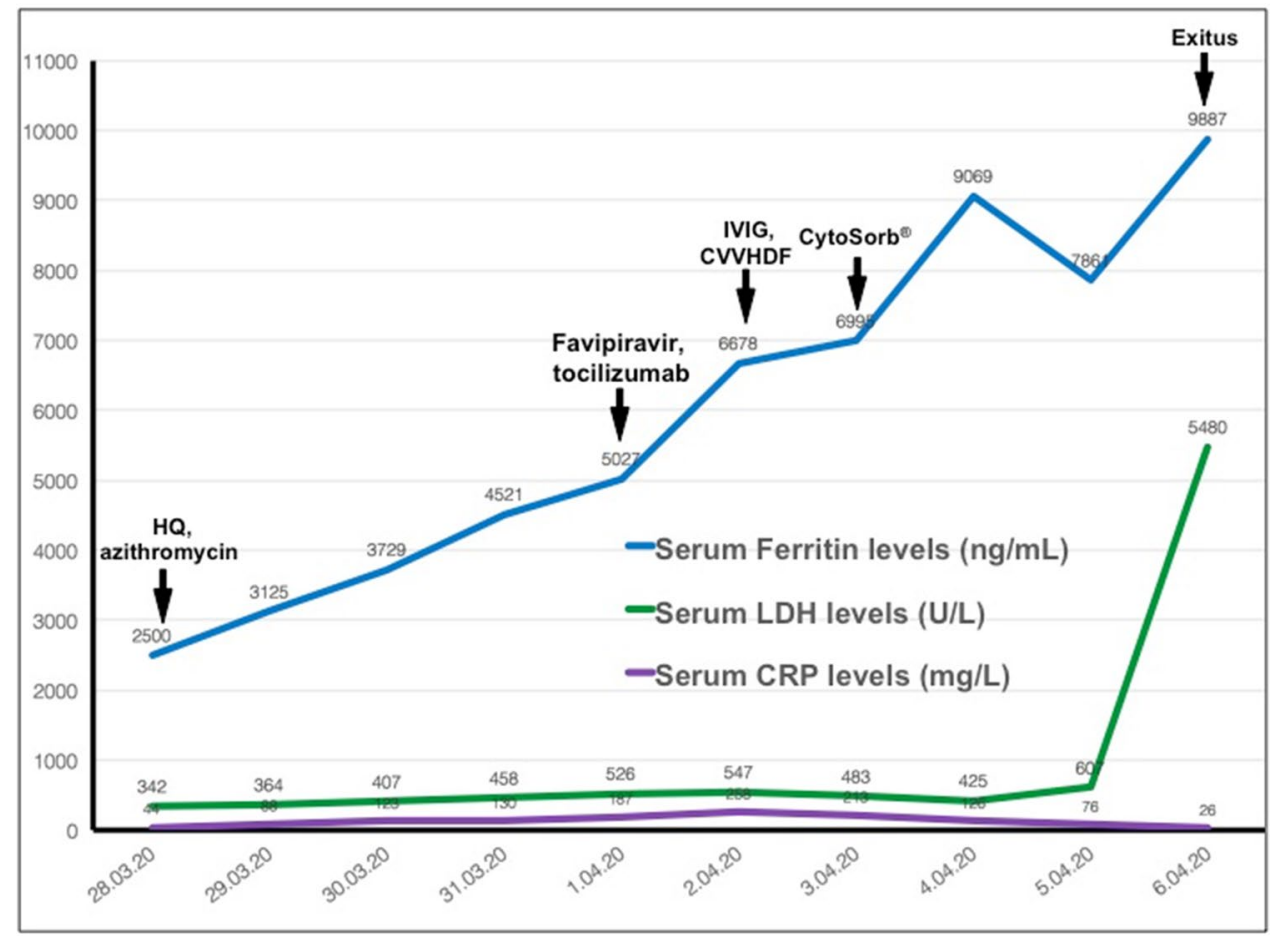

admission. Unfortunately, the second test could not be performed because of logistical problems.

The number of kidney transplant recipients with COVID19 is gradually increasing [6,7]. Prognosis and optimal treatment strategy of SARS-CoV-2 infection in transplant recipients remain uncertain. However, two new guidelines offered some recommendations for kidney transplant recipients with SARS-CoV-2 infection. These recommendations were based on demographic and clinical conditions such as age, fever, hypoxemia, and pulmonary infiltration. Guidelines suggest discontinuation of calcineurin inhibitors and antiproliferative agents with increasing the steroid dosage in hypoxemic patients. There is no consensus in milder cases. Hence, one of them recommends the withdrawal of calcineurin inhibitors and antiproliferative agents, while the other suggests the continuation of calcineurin inhibitors with halving the dose (through level 4-6 $\mathrm{ng} / \mathrm{ml}$ ) during SARSCoV-2 infection [6, 8]. Intriguingly, tacrolimus also has been shown to reduce the replication of coronaviruses in-vitro conditions [9]. We halved the tacrolimus dosage to prevent allograft rejection and also use a possible therapeutic effect for both SARS-CoV-2 infection and macrophage activation syndrome in the early clinical stable period $[9,10]$. Then, the calcineurin inhibitor was withdrawn due to deterioration of the clinical status on the subsequent days. Methylprednisolone was continued for the prevention of rejection and adrenal insufficiency.

Antiviral treatment recommendations in COVID-19 are limited due to poor data quality. Some research groups identified the effectiveness of antiviral drugs for the treatment, based on the experiences in the Middle East respiratory syndrome (MERS) and severe acute respiratory syndrome (SARS) outbreaks. Guidelines recommend hydroxychloroquine and remdesivir as the first-line treatments [11]. Lopinavir, ritonavir, darunavir, and favipiravir may be beneficial in refractory patients $[6,11]$. However, serious drug interactions have been reported between calcineurin inhibitors and lopinavir/ritonavir [8]. Favipiravir is a drug that acts by inhibition of RNA polymerase, which is approved by the Chinese pharmaceutical institution as an experimental treatment for SARS-CoV-2 infection [12]. We used hydroxychloroquine and azithromycin for the firstline treatment that could be a probable efficient therapy for SARS-CoV-2 infection [13]. Then, favipiravir added to the treatment due to clinical deterioration and the lack of remdesivir in our country.

Despite these treatments, multiorgan failure developed as a consequence of cytokine storm. It is one of the most important causes of death in SARS-CoV-2 infection. Monitoring of serum lactate dehydrogenase, ferritin levels, and cytopenias must be essential in all COVID-19 patients for early detection of the cytokine storm. Cytokine-targeted therapies such as anakinra (interleukin-1 receptor antagonist), tocilizumab (anti-interleukin-6 monoclonal antibody), and ruxolitinib (inhibitor of Janus Kinase 1/2) may be beneficial in COVID-19 patients with cytokine storm [14]. Another treatment, CytoSorb ${ }^{\circledR}$, is extracorporeal cytokine adsorber and is designed to reduce inflammation. It is also 
recommended in COVID-19 patients who received tocilizumab with acute kidney injury [6]. Additionally, IVIG may be a beneficial supportive treatment [15]. In our patient, we used tocilizumab as initial treatment for the cytokine storm. Then, IVIG was administered. After the deteriorating clinical situation, we also started CytoSorb ${ }^{\circledR}$ and CVVHDF therapy. Despite all our efforts, she had a fatal outcome.

In conclusion, COVID-19 is a severe infection that could cause mortality in kidney transplant recipients. We need qualified trials for new therapeutic options and modifying of immunosuppressive drugs and cytokine targeted therapies during SARS-CoV-2 infection, immediately.

Funding The authors declare no sources of funding for this study.

\section{Compliance with ethical standards}

Conflict of interest The authors declare no conflicts of interest.

Ethical approval This article does not contain any studies with human participants or animals performed by any of the authors.

Informed consent Informed consent was taken from the relatives of the patient.

\section{References}

1. Wan Y, Shang J, Graham R, Baric RS, Li F. Receptor recognition by novel coronavirus from Wuhan: an analysis based on decade long structural studies of SARS. J Virol. 2020;94(7):e00127e220. https://doi.org/10.1128/JVI.00127-20.

2. Onder G, Rezza G, Brusaferro S. Case-fatality rate and characteristics of patients dying in relation to COVID-19 in Italy. JAMA. 2020. https://doi.org/10.1001/jama.2020.4683.

3. Guan WJ, Ni ZY, Hu Y, Liang WH, Ou CQ, He JX, et al. Clinical characteristics of coronavirus disease 2019 in China. N Engl J Med. 2020. https://doi.org/10.1056/NEJMoa2002032.

4. Yang Y, Yang M, Shen C, Wang F, Yuan J, Li J, et al. Laboratory diagnosis and monitoring the viral shedding of 2019-nCoV infections. medRxiv. 2020. https://doi.org/10.1101/2020.02.11.20021 493(preprint article, published online).

5. Wikramaratna P, Paton RS, Ghafari M, Lourenco J. Estimating false-negative detection rate of SARS-CoV-2 by RT-PCR. medRxiv. 2020. https://doi.org/10.1101/2020.04.05.20053 355(preprint article, published online).
6. Alberici F, Delbarba E, Manenti C, Econimo L, Valerio F, Pola A, et al. Management of patients on dialysis and with kidney transplant during SARS-COV-2 (COVID-19) pandemic In Brescia, Italy. Kidney Int Rep. 2020. https://doi.org/10.1016/j. ekir.2020.04.001.

7. Akalin E, Azzi Y, Bartash R, Seethamraju H, Parides M, Hemmige V, et al. Covid-19 and kidney transplantation. NEJM. 2020. https://doi.org/10.1056/NEJMc2011117.

8. Maria O. Lopez-Oliva EG, Miranda RJ, Jimenes C. Management of kidney transplant immunosuppression in positive coronavirus infection requiring hospital admission 2020. https://www.eraedta.org/en/wp-content/uploads/2020/03/Management_of_kidne y_transplant_immunosuppression_LaPaz.pdf. Accessed 19 Mar 2020.

9. Carbajo-Lozoya J, Müller MA, Kallies S, Thiel V, Drosten C, von Brunn A. Replication of human coronaviruses SARS-CoV, HCoV-NL63 and HCoV-229E inhibited by the drug FK506. Virus Res. 2012;165(1):112-7. https://doi.org/10.1016/j.virus res.2012.02.002.

10. La Rosee P, Horne A, Hines M, von Bahr GT, Machowicz $\mathrm{R}$, Berliner N, et al. Recommendations for the management of hemophagocytic lymphohistiocytosis in adults. Blood. 2019;133(23):2465-77. https://doi.org/10.1182/blood.20188 94618.

11. Dong L, Hu S, Gao J. Discovering drugs to treat coronavirus disease 2019 (COVID-19). Drug Discov Ther. 2020;14(1):58-60. https://doi.org/10.5582/ddt.2020.01012.

12. Cai Q, Yang M, Liu D, Chen J, Shu D, Xia J, et al. Experimental treatment with favipiravir for COVID-19: an open-label control study. Engineering. 2020. https://doi.org/10.1016/j. eng.2020.03.007.

13. Gautret P, Lagier JC, Parola P, Hoang VT, Meddeb L, Mailhe $\mathrm{M}$, et al. Hydroxychloroquine and azithromycin as a treatment of COVID-19: results of an open-label non-randomized clinical trial. Int J Antimicrob Agents. 2020. https://doi.org/10.1016/j.ijantimica g.2020.105949.

14. Mehta P, McAuley DF, Brown M, Sanchez E, Tattersall RS, Manson JJ, et al. COVID-19: consider cytokine storm syndromes and immunosuppression. Lancet. 2020;395(10229):1033-4. https:// doi.org/10.1016/S0140-6736(20)30628-0.

15. Cao W, Liu X, Bai T, Fan H, Hong K, Song H, et al. High-dose intravenous immunoglobulin as a therapeutic option for deteriorating patients with coronavirus disease 2019. Open Forum Infect Dis. 2020;7(3):ofaa102. https://doi.org/10.1093/ofid/ofaa102.

Publisher's Note Springer Nature remains neutral with regard to jurisdictional claims in published maps and institutional affiliations. 